Multidisciplinary

SCIENTIFIC JOURNAL OF MARITIME RESEARCH

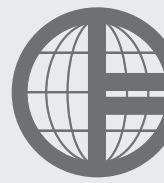

University of Rijeka

Faculty of Maritime

Studies Rijeka
Multidisciplinarni

znanstveni časopis

POMORSTVO

\title{
Users' Perception as a Tool for an Integrated Coastal Management and Beach Quality Assessment
}

\author{
Damir Magaš ${ }^{1}$, Borna Debelić ${ }^{2}$, Siniša Vilke ${ }^{2}$ \\ ${ }^{1}$ University of Rijeka, Faculty of Tourism and Hospitality Management, Primorska 42,51410 Opatija, Croatia, e-mail: damir.magas@fthm.hr \\ ${ }^{2}$ University of Rijeka, Faculty of Maritime Studies, Studentska 2, 51000 Rijeka, Croatia, e-mail: debelic@pfri.hr; svilke@pfri.hr
}

\section{ABSTRACT}

The aim of the paper is to show a brief review of social research methods used in beach user research and coastal zone management. It is argued that this approach may effectively be used from the perspective of Integrated Coastal Zone Management (ICZM). Beaches are one of the most important factors of the sun and sea tourism, and an area where the increased users ' pressure is common with the rise of tourist activity. This expansion creates increased pressure on the coastal area, the marine eco systems and, potentially, leads to a degradation of the natural environment. Social research methods provide an invaluable insight into the processes incentivizing beach users in respect to physical, social, economic and natural aspects of beach uses as well as of other parts of the coast, through the concept of the user perception. The intended result is to provide a brief methodological overview of social science research methods applied to and found in literature that can be used to be better informed of the beach management decisions as an area of ICZM interest and, in this way, contributing to the overall sustainable development of the coastal zone and increasing the competitiveness of beach tourism.
\end{abstract}

\section{ARTICLE INFO}

Review article

Received 15 November 2018

Accepted 12 December 2018

\section{Key words:}

User perception

Maritime common good

Coastal zone management

Beach quality assessment

Tourism and entrepreneurship development

\section{Introduction}

Public participation is the main step in the planning process of coastal management (Water Framework Directive; 2002/413/EC "Recommendation of the European Parliament and Concerning the Implementation of ICZM") and the Integrated Coastal Zone Management (ICZM) protocol represents a solid institutional foundation for the expression of the Barcelona convention impact onto coastal zone management. The most effective way to achieve sustainable development is to implement a participative stakeholder inclusive approach [12], [11], [5], [6] in governing of the commons [12], [11], [5], [6], [9]. An initial step for this undertaking would be to acquire the understanding of public attitudes and perceptions [17]. It is not only a good starting point but also an impact assessment tool of the planning process thus far. The results of the beach user surveys can be used to measure the quality of beaches as perceived by the users (users in this paper are tourists and the local population), considering the col- lected data on physical, social, environmental and service related aspects. New policies and interventions can then be tailor-made for specific beach sites on the basis of the collected results.

Beaches are socio-ecological systems where plainly physical, ecological, social and economic dimensions interact, providing several functions and services to improve human wellbeing like erosion control, protection from floods, biological control and supplying recreational as well as cultural services [4], [3]. The complexity of these factors interaction at the beach location level can be observed and measured in the resulted cumulative user perceptions of each of these dimensions. This data driven approach can contribute to the sustainable development of beaches, increase the beach management effectiveness and promote higher satisfaction levels of beach users. This approach enables a data driven participative sustainable development of a complex natural system that constitutes the basis of the classic sun and sea tourism product. 


\section{Theoretical Background}

The coastal zone is a special form of resource due to its size, variety and complexity of structure as well as its importance for the maritime economy, and quality of life in a coastal area [6]. This influences the diversity of local living and working conditions. Considering the economic and social importance of coastal zones and their integrated resources, as well as the breadth of economic issues and coastal zone management features, the maritime common good [5], [6] represents the comprehensiveness of life, work, resources and area in the sea and by the sea, taking into account the sea and the coastal zone, and all that is connected to them, as an inseparable integral unity to achieve the desired effects, while preserving its sustainability to the benefit of the entire society and with an open access to everyone in accordance with the purpose of maritime good and institutional arrangements as well.

The maritime common good and its allocative complexity has been analysed by Debelić [6] from multiple perspectives: the functional, socio-cultural and institutional one, and, the last one, the ecological perspective, emphasizing that the complexity itself and the immanent characteristics of the maritime common good impose a potential problem of an excessive and uncontrolled exploitation, usurpation and general devastation, recognized as a problem of governing the commons. The need to seek for theoretically founded and empirically feasible solutions in order to overcome the Hardin's "tragedy of the commons" has been emphasized in the light of modern theories of self-governance, including deliberative governance, as well as participative management. In addition, the need for further improvements in maritime common good governing mechanisms, that can be based on the stakeholders' inclusion into decision-making processes, thus strengthening the potential of the mechanisms itself and the information background necessary for a successful management of coastal zones, has been recognized. This can help to overcome the variety of collective decisionmaking problems that are strongly correlated with allocation problems within coastal zones. Beaches are a specific part of coastal zones, important for sustainable tourism development and growth as well as for maritime economy in general.

\section{Overview of the Beach User Research Methodology and Approaches}

One of the earlier researches to apply the study of beach user perception has been carried out by Breton et al. [2]. The authors' hypothesis has been that social and ecological functions of the beaches can be optimized by exploring the preference of their users and their attitudes towards the beach they visit, as the feedback from the users on the results of the policies that have been implemented. This approach is much more effective than estimating the number of visitors and synthetically calculating services and content relative to their number. Understanding the users' behaviour, with a focus on improving the negative aspects of their experience, in order to adapt the levels of environmental variables use to the environment [7] or, in other cases, investigate the capacity of the users to contribute and improve management of specific locations.

In summer (18 days), in the metropolitan area of Barcelona, a survey has been carried out using a questionnaire ( $\mathrm{N}=1200,4$ beaches) as well as a deep interview method (20) with people whose work is related to beaches. In-depth interviews have allowed to situate the results of the research into a wider context, and having a set of subjective observations of the beach itself enables a more accurate interpretation of the research results [2]. Information collected from the questionnaire have been: (1) Weather and sea conditions on the day of the testing: date, location, precise location. (2) Socio-demographic data of the respondents (age, sex, place of residence, status of employment, level of education. (3) Beach data; (3.1) General habits for going to the beach. (3.2) Beaching habits where the testing took place (a) in the peak season (b) in the off-season. (3.3) Beach use on the day of the testing (arrival method, length of stay, company, things taken to the beach, types of activities on the beach); (3.4) Services and other contents used on the beach, opinion on the quantity and quality of the content; (3.5) General opinion of the beach and what is their ideal beach.

Although no unique user's profile has been found, the results obtained have suggested that the user's homogeneity exists with respect to a specific beach; certain types of beaches are much preferred by older people, other by families with children, while some are preferred by couples and/or groups of young people. There are significant differences in the socio-economic classes, the education level and the place of residence of the users. These results imply a specific type of the user's concentration in relation to the beach type or location. It is interesting to note that, in the time this research has been carried out, most of the users came from the same municipality as the beach is situated at or from the inland municipalities and Barcelona.

Almost a decade later, under a project funded by the Ministry of Education and Science of Spain - MeVaPlaya [13] and built on the previous work, the public perception for evaluating beach quality in urban and semi-natural environments has been examined They have argued that a better understanding of the users ' perception of the beach quality can be very relevant for beach managers in deciding upon a certain strategy towards the integrated coastal management. This can complement the top-down approach to eco certification (Blue Flag) as the main drawbacks of these eco certification scheme is that there is no input from the beach users' views, preferences or perception. The area of research has been the Costa Brava located $100 \mathrm{~km}$ to the north of Barcelona. They have sampled 6 beaches, $n=700$. The sample has represented a random group of visitors on each beach in one weekend of the main season (in July). Random sampling has been based 
on a set path including the entire width of the beach that the interviewers followed in a zigzag fashion, thus covering the whole beach area. The results obtained have shown the identification of preferences for choosing a beach type (urban or semi-natural). It has been found that vicinity ( $21 \%$ for urban and $29 \%$ for semi-natural beaches) and scenery, with more or less similar results $(22 \%$ for urban beaches and $23 \%$ for semi-natural ones) play a key role. Regarding scenery as a motivational factor, Tunstall and PenningRoswell [18] have pointed out that even in the man highly altered beaches, the perceived natural coastal landscape is highly appreciated and significantly guides the people's choice, which also includes the tourist destination behind the beach and the immediate surroundings. Tranquillity has been a stronger factor for choosing semi-natural beaches (12\%), while recreational activities have been more important (5\%) for the urban beach type. The user's satisfaction with the physical dimensions of a beach has been significantly lower for beaches in urban areas. Two factors influencing higher dissatisfaction levels have been identified as: 1. overexploitation of the beach area (rental equipment, boats placed on the sand, stalls, etc.); 2 . erosion problem. They have concluded that these two factors may lead to a feeling of overcrowding. The beach slope into the sea is a factor perceived differently regarding the beach type. In urban environments, this item has received the lowest mark because the users desire a gently morphology in accordance to the massive public use, while in more natural environments, the slope is not so negatively perceived, because the users there prioritize the natural experience over a comfortable recreational experience. This research has confirmed that the users tend to cluster on beaches in regard to the beach type and that their perceptions are the result not only of the beach type but also of the profile of the beach users. The results regarding beach management practice have implied that recreational functions and facilities need to be emphasized in urban beaches while conservation measures and nature are a priority of semi-natural and natural environments. Caution is advised, however, as overexploitation by amenities and facilities at the beach are a strong factor of the beach users' dissatisfaction.

Roca et al. [15] have also performed a non-hierarchal cluster analyses to detect the opinion of the groups of beach users using contingent tables and chi-squared test in order to detect correlations with sociodemographic and behavioural variables of the beach users. The area of research has been the same as in [13].

A non-hierarchical cluster analyses has been performed, and two cluster results have been obtained. The first group - demanding beach users (coming from the same municipality where the beach is located or from other parts of the region) has shown some sort of dissatisfaction. Although around $50 \%$ of the items have shown a satisfactory level of acceptability, only 4 are closer to or above 7. These lower values have indicated dissatisfaction with some services and facilities such as for example the parking areas. Toilet facilities have been found to be scarce, not clearly marked or with insufficient mainte- nance. They have perceived the beach and the seawater as unclean ones thus suggesting inadequate maintenance. Regarding natural elements, they have perceived algae and fish scarce and non-existent. Finally, they have perceived noise from people and car engines as annoying. Satisfaction has been manifested with elements such as dimension of the beach, colour of the sand and visual scenery. The second group, the satisfied beach users, including foreign tourists, adults and elderly people, has expressed a high degree of satisfaction through the whole list of items. Scores have been above 7 in more than $80 \%$ of the investigated cases. The best scores correspond to items such as scenery, comfort, quality/price and number of users.

The results have shown a significant statistical difference in the perception between local population and foreign visitors, the tourists. Local population and the Catalan users are more concerned about natural beach characteristics and environmental degradation and are also more demanding regarding the facilities and equipment. Foreign visitors, having a short stay, are satisfied with all items and do not feel disturbed by overcrowding. The conclusion of this research can be summarized in the fact that there are sociodemographic determinants that effect the beach users' perception. If these determinants can be extrapolated from the beach users' population, the general population can be clustered into opinion groups from which relevant information for coastal managers can be created.

Lozoya et al. [8] have analysed the users' expectations and their needs for differential beach management frameworks, so that their work aimed at reverting homogenization and promoting a sustainable beach management. The research has assessed and compared the users' expectations and perceptions in two different beach types of the Costa Brava (urban setting vs. protected setting), in order to identify particular requirements that could imply the necessity of differential management regarding the beach type [8]. This research has followed the previous research concerning the users' perception and how it can lead to linking specific users to a beach type. The research area has been again Costa Brava in Spain, including two beaches: S'Abanell beach (urban and unprotected setting) and Sant Pere Pescador (natural and protected setting). With reference to the semi-natural beach setting, researched by Roca and Villares, the protected beach site used in Lozoya et al. is a part of the NATURA 2000 network as a Special Protection Area (SPA) so it is a protected natural area in European and Spanish legislation. In order to assess the motivations, experiences and priorities of the beach users, a research has been carried out. Questionnaires have been prepared based on [13], [14], [15] with examples from literature [16], [1]. The authors' contribution to the methodology has been to add a section regarding the "willingness to pay" concept and questions about personal incomes. The results have been analyzed by the IBM SPSS software package. The basic descriptive analysis has been carried out through the analysis of mean, median, st. deviation as well as through basic percentages for each parameter of both beaches, as can be seen on Figure 1 . 

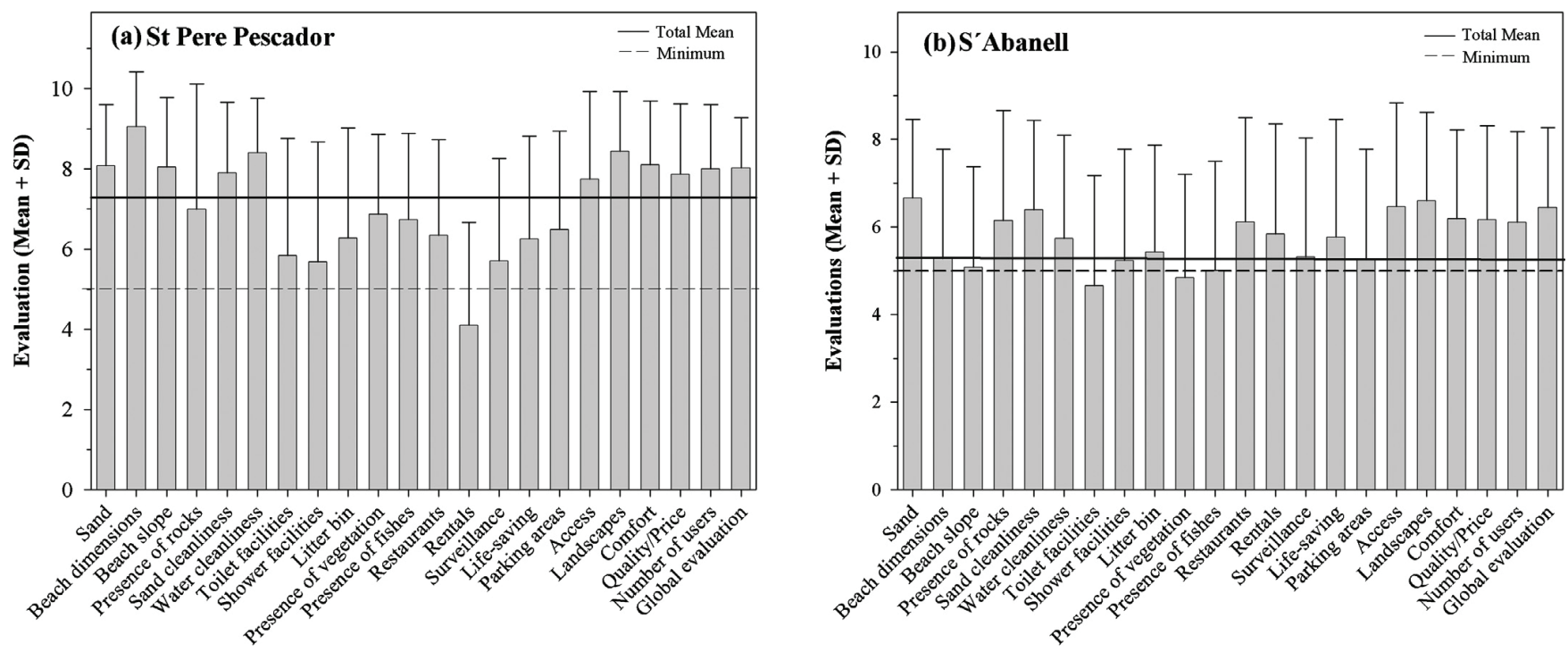

Figure 1 Users` perception based on mean evaluation

Note: Solid lines represent the total mean evaluation and dotted lines show the minimum acceptable evaluation.

Source: Lozoya J. P., Sardá R., Jiménez J. A. (2014). Users expectations and the need for differential beach management frameworks along the Costa Brava: Urban vs. natural protected beaches, Land Use Policy Vol. 38, p. 397-414.

For comparison of the data obtained from both beaches, z-test and chi-squared test have been used depending on the characteristics of the analyzed variable. The users of both beaches have been mostly Spaniards. On the protected beach, the share of foreign tourists has been higher $-40 \%$, than on the urban beach $-26 \%$. The percentage of the users with higher incomes has been higher on the protected beach $-34 \%$, than on the urban beach $-26 \%$. Although most of the respondents have been students on both beaches, $43 \%$ of them had a MA (Master) degree on the protected natural beach, suggesting that the natural beach is more attractive to users with higher levels of education. The percentage of users expressing their willingness to pay has been significantly higher in the natural and protected beach then in the urban beach type.

The Z-test has confirmed the main hypothesis that users with preferential priorities to "nature", "untouched habitats" and "silence" are grouped on the natural beach. On the urban beach, users prioritize "good content", "certificate quality", "proximity" and "access and parking". The main priorities on both beaches have been "cleanliness" and "comfort and safety". It is interesting to note that users have evaluated poor beach facilities on the urban beach winner of the Blue Flag award. Evaluations of services have been more positive on the protected beach, offering very limited services (authors convey that this beach has no rentals, toilets nor showers). Nevertheless, in the open end question asking the users the worst aspect of the beach, the most often replies for the natural protected site have been: "No showers", "No toilet". This can be a problem of importance to the user, as the user perceives the problem only in regard to the questionnaire or the particular question, he may not have in mind, in that moment, that the increased services will most likely lead to degradation of their own priorities i.e. nature, untouched habitats and silence. It could be of importance to point out some cost-benefit references to the user in forming these types of questions regarding services on natural - protected sites in order to better inform the user of the wider effects, in the moment of answering the question.

The elements that have been introduced into the methodology by Lozoya et al. [8] are certainly a contribution to, but there are some problems in overlapping the questionnaire design. Namely, eliciting the users' perceptions on the lack of services on the protected beach settings, without the users having more information on probable overall consequences to the beach itself (erosion) with the introduction of these services as well as to the elements they perceive as important (beach space availability, noise and untouched habitats) may be biased. Another important variable regarding the users' perception of beaches is beach occupancy. Roca et al. [14] has carried out the case study in the Costa Brava, Spain, in which they have examined how beach occupancy effects the users' perceived quality of beaches. The level of beach coverage is quantified by collecting data at the time of maximum use. The collected data have been compared with an optimum carrying capacity. Furthermore, the users' profiles have been established for each beach as well as levels of recreational experience, satisfaction and public perceptions have been estimated. This has been done through researches on every beach. The users have evaluated both physical and ecological aspects, as well as those associated with content, beach position and grading. The results of these two approaches have been combined in order to identify any correlation or repetitive pattern between beach occupancy and the user's perception of the beach. 
Six beaches of the north-eastern region of the Catalan coasts have been selected: three urban beaches, two seminatural beaches with a good access and one natural beach with a reduced access. Although the chosen beaches are close to each other and located in the same region (Costa Brava), they have been differentiated in relation to the physical size of the beach itself and the degree of development of the immediate surroundings.

A direct observation has been used in order to analyze the beach occupancy. Visitors have counted within the 30 $\mathrm{m}$ wide beach plots distributed at regular intervals along the entire beach. The total of the beach users within the $30 \mathrm{~m}$ beach plots and the adjacent water area have been registered. The calculations took place in August on weekends and holiday days with good weather conditions [14].

The hypothesis that the degree of occupancy of the beach area, i.e. level of occupancy, has an impact on the level of satisfaction of the beach user has been tested. In other words, does the much larger amount of available beach area positively affect the users' satisfaction? In order to test this hypothesis, the mean value of space availability and the mean value of the customers' satisfaction have been assessed through regression analyses. The coefficient of determination $\mathrm{r} 2=0.555$ is satisfactory which means that the model explains $55 \%$ of the variation. However, the probability value is $\mathrm{p}>0.05$. Roca et al. have attributed this to a small number of observations. The regression line with fitted observations is shown in Figure 2.

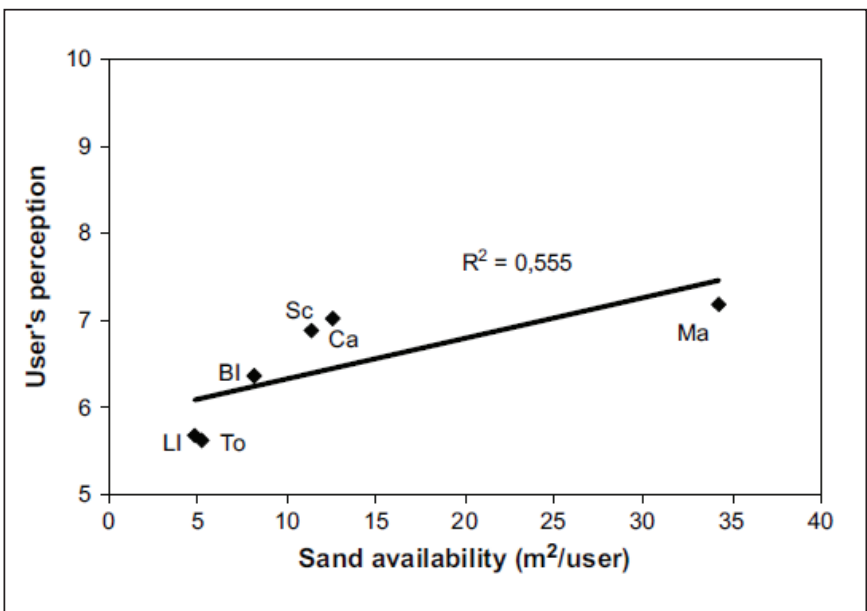

Figure 2 Correlation between sand availability and beach user satisfaction based on user density

Source: Roca E., Riera C., Villares M., Fragell R. \& Junyet R. (2008). A combined assessment of beach occupancy and public perceptions of beach quality: A case study in the Costa Brava, Spain. Ocean \& Coastal Management

Significant variations in the $\mathrm{m}^{2} /$ user mean indicator have been found ranging from $4.83 \mathrm{~m}^{2} /$ user to $34.2 \mathrm{~m}^{2} /$ user. It has been established that the level of urbanization influences the availability of beach area by the user. Thus, the lowest values measured at the beaches of Lloret and Tossa with the lowest average availability values of
$4.83 \mathrm{~m}^{2}$ per user and $5.16 \mathrm{~m}^{2}$ per user. These results have come close to the carrying capacity thresholds for urban beaches from the literature (between 4 and $6 \mathrm{~m}^{2}$ per user). It has also been established that the most pristine beach has available $11.33 \mathrm{~m}^{2}$ per user, which is not much for a natural beach, but is within the limits of recommendation for this type of a beach (from 10 to $15 \mathrm{~m}^{2}$ per user).

The matching of the beach occupancy data and users' perception has shown that, contrary to what might have been expected, high levels of occupancy do not necessarily lead to low levels of satisfaction. Other parameters (e.g., physical characteristics, landscape, facilities) are also important in the perceived beach quality from the perspective of the beach users [14].

A study of the users' perceptions of the sustainable beach management performed in Italy [10] is an interesting addition to this research as it incorporates insights from Italy into this synthesis. The research is aimed at defining the users ' profiles, their perception and awareness about issues related to the beach. As no previous data on the beach users' perceptions has existed within the researched area, the results obtained could be useful as the basis for further research and as support for both local and public authorities as well as private managers (beach concessionaires). Another important dimension mentioned here is concession on the beaches as previous research on beach user perception does not incorporate this item.

The questionnaire has been carried out in the area of 6 municipalities of Riviera del Beigua (Italy, near Genova). The general characteristics of the area correspond to a typical sun and sea destination with local tourism being characterized by family-oriented domestic tourism. The questionnaire has been prepared on the basis of examples from the literature, taking into consideration past experiences in the Ligurian area and through formulating new questions on the basis of local peculiarities and specific needs [10]. The questionnaire structure has been the following one: a) general section of the users ' profile identification; b) a section for assessing the users' perception and attitude about the beach; c) a section aimed to investigate the users' awareness and knowledge about issues related to beach management.

In the first attempt, questionnaires have been delivered to people in charge of private beaches with entrance fee or to bars in the vicinity of public beaches. The return rate of these respondents has been $30 \%$. In another attempt, a minimum of 90 questionnaires for each municipality have been delivered directly to the users found on the beaches, both in private beaches with entrance fee and public ones and they were recollected after a few minutes. In total, 528 questionnaires have been collected. $80 \%$ of the returned questionnaires have been those collected from private beaches with entrance fee. This has been mainly due to a low number of public beaches in the area. The results have been first analysed for each municipality alone and after that they have been aggregated to the whole district.

The users' profile results have indicated that the beach users are aged 36 - 50 and $70 \%$ have been women. Regarding their level of education, more than half of 
them have graduated from secondary school $56 \%$, while $22 \%$ have had a university degree. Around $33 \%$ of the users have been residents and $67 \%$ of them tourists. They have valued the importance of beaches, as compared to other aspects of the holiday, as a high one for $56 \%$ and as a medium for $42 \%$ of the users. The order of priorities obtained (max. 3 preferences per user) has been the same for public and private beaches. The users have considered sea and beach cleanliness more important than other options. Service, facilities and the type of beach sediment emerged as the second and third preference. Considering the factors of disturbance, dirty sea and garbage on the beach have been indicated as the first and second worst factors, while crowds on the beach have been perceived as the third negative issue. On an average of $68 \%$, the interviewed users have considered the overall beach quality to be a good one. Water quality has been regarded as a sufficient one, on an average of $49 \%$ questioners. The percentage of the beach users have perceived the quality of water as a remarkable increase because the sampling location has moved further in distance from the city of Genoa. Submarine landscape has perceived just as a sufficient one or even poor for the majority of the beach users $-69 \%$. Space available at the beach has not been perceived as a sufficient one, different perception have been registered between the users of private (44\%) or public beaches (19\%). Regarding willingness to pay to improve the beach quality, $36 \%$ of the respondents have agreed to pay if the funds were to be used to maintain or improve beach quality. This percentage is the same for both residents and tourists.

Beach users of the Riviera have expressed a negative opinion of the local seascape. This has been perceived as just sufficient or even poor by almost two thirds of the respondents. Marin et al. have conveyed that this opinion fits with the "objective situation" of the area, which the authors have described as a situation where high anthropocentric pressure has led to „banalisation“ of the coastal environment. A dedicated section of the questionnaire has been aimed at evaluating the beach users' awareness of beach nourishment, Blue flag award and environmental certification. $55 \%$ of the users have reported they do not know what beach nourishment is. Among the negative effects evaluated, the possible reduction of the beach sand quality has been perceived as the highest risk. $81 \%$ of the respondents have reported that they know what a Blue flag is and $28 \%$ of the respondents have said to be familiar with ISO 14001 accreditation and EMAS registration.

The methods used by Marin et al. [10] are primarily descriptive and as such the results have a lower level of significance to beach management practice as opposed to more quantitative methods of the Spanish authors [13], [14], [15]. Marin et al. [10] contribution can be primarily identified in regard to incorporating new attributes of the users' perception regarding public and private (concession) management practice. A useful insight into is the fact that the users have reported a significant difference of perception between beach space available at public as opposed to private (concession) beaches. This could indi- cate a tendency of overexploitation of the beach area with facilities by private (concession) management implying that it could lead to lower levels of satisfaction of the users on concession beaches. As the authors, regarding this issue, have performed no statistical significance tests, more data and further research is required for conclusions to be made. Another important contribution is the introduction of the Blue flag variable as this certification scheme relevance to the users' perception and beach quality can be evaluated. Marin et al. [10] have examined the users' knowledge on the scheme, but have not investigated has the Blue flag certification led to higher satisfaction levels, which is also an area of interest for beach managers.

\section{Conclusion and Discussion}

We have reviewed different approaches to the measuring of the users' perceptions of beach quality and have demonstrated why this methodology has contributed to ICZM. The selected researches have shown how social characteristics determine the users ' perceptions and influence the particular beach type they prefer. This has strong implications concerning the cost-benefit aspect of the beach planning decisions, as clustering beach facilities leads to erosion problems and to a perceived overexploitation of the beach area, even on large urban beaches. While on natural beaches, it can lead to their environmental degradation and may influence lesser levels of satisfaction of more educated and wealthier users. These types of users, as shown, prefer this beach type. In order to make better-informed decisions, analytical data are important for managers, and a beach quality assessment is best realized using different parameters in an outcome driven approach. The use of social science research methods has contributed to bottom up decision-making processes and to promote users' as stakeholders in the planning process. With physical and biological parameters traditionally assessed, the users' perception can contribute to a more holistic understanding of the present situation and to a more market- and data-based public management practice where integrated planning decisions have led to higher users' satisfaction levels, higher quality coastal area and a more competitive and sustainable tourism destination. In order to contribute significantly to beach management and to the sustainable development of beaches, the data-driven approaches shown in this research can be increased and scaled to longitudinal, site specific research carried out annually, the results being published as an open database.

With the site specific annual research, significant applicative values for public and private decision-makers can be derived, resulting in the data driven participative decision-making while fostering further research on the topic of the beach quality in a destination, regional or country based approach.

This could have long run positive implications on beach quality, higher user satisfactions and competitiveness of small countries or regions highly dependent on sun and sea tourism. 


\section{References}

[1] Blakemore, F. B.,Williams, A. T. (2008). British tourists' valuation of a Turkish beach using contingent valuation and travel cost methods, Journal of Coasal Research, 24(6), pp. 1469-1480.

[2] Breton F., Clapes J., Marques A.,Priestley G.K. (1996). The recreational use of beaches and consequences for the development of new trends in management: the case of beaches of the Metropolitan Region of Barcelona (Catalonia, Spain). Ocean and Coastal Management, Vol. 32, No. 3, pp. 153-180.

[3] Costanza R., d`Arge R., de Groot R., Farberk S., Grasso M., Hannon B., Limburg K., d Naeem S., O`Neill R., Paruelo J., Raskin R.G., Sutton P., Van den Belt M. (1997). The value of the world`s ecosystem services and natural capital. Nature, 387 , pp. 253-60.

[4] De Groot R. (1992). Functions of Nature: Evaluation of Nature in Environmental Planning, Management and Decesion-making, Wolters Noordhoff BV, Groningen, p. 315.

[5] Debelić, B., (2013). Racionalizacija mehanizma alokacije pomorskog dobra republike hrvatske (doktorska disertacija). Rijeka: Ekonomski fakultet Sveučilišta u Rijeci.

[6] Debelić, B. (2018). Maritime Common Good and Coastal Zone Management, Pomorstvo - Scientific Journal of Maritime Research. 32, 1., pp. 151-161.

[7] Hecock, R. D. (1983). Recreation Behaviour Patterns as Related to Site Characteristics of Beaches, Journal of Leisure Research, 15, pp. 37-250.

[8] Lozoya J. P., Sardá R., Jiménez J. A. (2014). Users expectations and the need for differential beach management frameworks along the Costa Brava: Urban vs. natural protected beaches, Land Use Policy Vol. 38, pp. 397-414.

[9] Mance, D., Vretenar, N., Katunar, J. (2015). Opportunity Cost Classification of Goods and Markets. International Public
Administration Review. Available at SSRN: https://ssrn. com/abstract $=2675979$.

[10] Marin V.,Palmisani F., Ivaldi R., Dursi R., Fabiano M. (2009). Users' perception analysis for sustainable beach management in Italy, Ocean \& Coastal Management, 52/5, pp. 268-277.

[11] Ostrom, E., (2010). Beyond Markets and States: Polycentric Governance of Complex Economic Systems. American Economic Review, 100 (3), pp. 641-672.

[12] Ostrom, V., Ostrom, E., (1977). Public Goods and Public Choices, u: Savas, E. S. Alternatives for Delivering Public Services: Toward Improved Performance. Boulder: Westview Press, pp. 7-49.

[13] Roca E, Villares M. (2008). Public perceptions for evaluating beach quality in urban and semi - natural environments, Ocean \& Coastal Management, 51, pp. 314-329.

[14] Roca E., Riera C., Villares M., Fragell R. \& Junyet R. (2008). A combined assessment of beach occupancy and public perceptions of beach quality: A case study in the Costa Brava, Spain. Ocean \& Coastal Management, pp. 239-46.

[15] Roca, E., Villares M. \& Ortego M. I., (2009). Assessing public perceptions on beach quality according to beach users ' profile: A case study in the Costa Brava (Spain), Tourism Management, Volume 30/4, pp. 598-607.

[16] Togridou, A., Hovardas, T. \& Pantis, J.D. (2006). Determinants of visitors' willingness to pay for the National Marine Park of Zakynthos, Greece. Ecological Economics, 60(1), 308-319.

[17] Tran K. C., Euan J., Islac M.L. (2002). Public perception of development issues: impact of water pollution on a small coastal community. Ocean \& Coastal Management, 45, pp. 405-20.

[18] Tunstall, S.M. and Penning-Roswell, E.C. (1998). The English beach: experience and values. Geographical Journal, 164(3), pp. 319-332. 